\title{
Cytoskeletal changes during epithelial-to-fibroblastoid conversion as a crucial mechanism of des- $\gamma$-carboxy prothrombin production in hepatocellular carcinoma
}

\author{
KAZUMOTO MURATA ${ }^{1}$, HIDETO SUZUKI ${ }^{1}$, HIROSHI OKANO ${ }^{3}$, TAKASHI OYAMADA ${ }^{1}$, \\ YOSHIKAZU YASUDA ${ }^{2}$ and ATSUSHI SAKAMOTO ${ }^{1}$ \\ ${ }^{1}$ Center for Community Medicine, ${ }^{2}$ Department of Surgery, Jichi Medical University, 3311-1 Yakushiji, \\ Shimotsuke, Tochigi 329-0498; ${ }^{3}$ Department of Internal Medicine, Suzuka Chuo General Hospital, \\ 1275-53 Yamanohana, Yasuzuka, Suzuka 513-8630, Japan
}

Received April 9, 2009; Accepted June 2, 2009

DOI: 10.3892/ijo_00000415

\begin{abstract}
Des-gamma-carboxy prothrombin (DCP) is a well-established tumor marker for hepatocellular carcinoma (HCC), but the precise mechanism by which HCC cells produce DCP remains unknown. Our preliminary experiments demonstrated that HepG2 cells with chemical induction of epithelial-to-fibroblastoid conversion (EFC) produced DCP through impairment of vitamin $\mathrm{K}$ uptake via cytoskeletal rearrangement. Therefore, in this study we further examined this mechanism in vitro and using human HCC samples. Hepatoma cell lines (HepG2 and PLC/PRF/5) were induced EFC or epithelial-mesenchymal transition (EMT) by phorbol 12-myristate 13 acetate (TPA) or transforming growth factor (TGF)- 31 . We analyzed these cells by ELISA, Western blotting and immunofluorescent studies. We also examined DCP production and E-cadherin expression in human surgically resected HCC samples by immunohistochemical studies. Labeled low-density lipoprotein (LDL) uptake (as a surrogate for vitamin $\mathrm{K}$ ) was significantly impaired in DCP-producing hepatoma cells following induction of EFC or EMT. Further, filamentous actin, which plays a critical role in clathrinmediated endocytosis, was dissociated in DCP-producing cells. Latrunculin A, an actin depolymerizer, induced naïve hepatoma cells to produce DCP with impairment of labeledLDL uptake. In addition, an E-cadherin neutralizing antibody did not induce DCP production. Finally, immunohistochemical studies demonstrated that DCP production was inversely correlated with the intensity of E-cadherin expression in human
\end{abstract}

Correspondence to: Dr Kazumoto Murata, Center for Community Medicine, Jichi Medical University, 3311-1 Yakushiji, Shimotsuke, Tochigi 329-0498, Japan

E-mail: atarum@jichi.ac.jp

Key words: des- $\gamma$-carboxy prothrombin, hepatocellular carcinoma, vitamin $\mathrm{K}$, clathrin-mediated endocytosis, epithelial to fibroblastoid conversion, filamentous actin rearrangement
HCC cells. In conclusion, cytoskeletal changes during EFC or EMT plays a critical mechanistic role in DCP production via impairments in vitamin $\mathrm{K}$ uptake.

\section{Introduction}

Prothrombin is a vitamin K-dependent blood coagulation protein that is synthesized only in the liver, and the biological active form of prothrombin is dependent on the use of vitamin $\mathrm{K}$ as a cofactor in the posttranslational carboxylation of specific glutamyl residues of prothrombin precursor (1). In the absence of vitamin $\mathrm{K}$, or when its action is antagonized by vitamin $\mathrm{K}$ antagonists, abnormal prothrombin (des- $\gamma$ carboxy prothrombin, DCP), also known as 'protein induced by vitamin K absence or antagonist II' (PIVKA-II), is released into the blood $(1,2)$. DCP is a well-established tumor marker for hepatocellular carcinoma (HCC) (3). Several authors have suggested that DCP production in HCC cells requires a reduction of $\gamma$-carboxylase gene expression (4), excessive synthesis of prothrombin precursors (5) or reduction of vitamin $\mathrm{K}$ content (6). However, the precise mechanism by which HCCs produce DCP remains unclear.

Cell migration is an essential function in various physiologic processes, including wound healing, as well as in pathophysiologic processes, such as tumor cell invasion and metastasis (7). Cancer cells can gain migratory and/or invasive properties when they were exposed to noxious stimuli, such as chemicals (8) and hypoxia (9), in an attempt to escape from an unfavorable microenvironment. In these situations, cancer cells lose their epithelial properties and acquire mesenchymal properties. This phenomenon is known as epithelial-mesenchymal transition (EMT) (10), which is a process initially observed in embryonic development. Recently, we showed preliminary experiments that HepG2 cells with chemical induction of epithelial-to-fibroblastoid conversion (EFC) produced DCP through impairment of vitamin K uptake via cytoskeletal rearrangement (11), suggesting that HCC cells may change their phenotype to produce DCP when they gain the migratory or invasive properties. Here, we attempt to further examine the mechanism of DCP production in vitro and investigate using human surgically resected HCC samples. 


\section{Materials and methods}

Cell culture. Hepatoma cell lines, HepG2 and PLC/PRF/5 cells, were maintained in Dulbecco's modified Eagle's medium (DMEM) containing 10\% fetal calf serum (FCS). For immunofluorescence studies, cells were cultured in chamber slides (Nagle Nunc International, Rochester, NY).

Enzyme-linked immunosorbent assay (ELISA) for DCP. Cells were seeded at a density of $2 \times 10^{5}$ cells into 24 -well plates. The next day, the medium was replaced with medium containing various concentrations of phorbol 12-myristate 13 acetate (TPA) (Sigma, St. Louis, MO), transforming growth factor (TGF)-B1 (R\&D Systems, Minneapolis, MN) or $1 \mu \mathrm{M}$ latrunculin A (Lat A) (Sigma) with or without vitamin K2 (Sigma), and the cells were cultured for a $24 \mathrm{~h}(48 \mathrm{~h}$ for TGF-B1). In other experiments, cells were cultured with $500 \mu \mathrm{g} / \mathrm{ml}$ of suramin (Sigma) with or without $100 \mathrm{nM}$ vitamin K2. Cells were also treated with $3 \mu \mathrm{g} / \mathrm{ml} \mathrm{SHE78-7}$ (Takara, Tokyo, Japan) or control IgG (BD Biosciences, San Jose, CA) for $48 \mathrm{~h}$. The supernatant of the culture medium was subjected to ELISA for DCP. Control cells were incubated with $10 \%$ DMEM containing $0.1 \%$ DMSO (control for TPA), or $10 \%$ DMEM containing $4 \mathrm{nM} \mathrm{HCl}$ (control for TGF-ß1). The DCP concentration was determined using a PIVKA-II ELISA kit (Eisai, Tokyo, Japan) according to the manufacturer's instructions.

Immunofluorescent microscopy. After cells were fixed with $4 \%$ paraformaldehyde, primary antibodies were applied overnight at room temperature. Anti-rabbit E-cadherin (1:50, IBL Co., Fujioka, Japan) or anti-mouse PIVKA-II (anti-DCP) (MU-3, 1:100, a kind gift from Eisai, Co., Japan) were used as primary antibodies. After washing, the cells were incubated with FITC-conjugated rabbit IgG (Sigma) or AlexaFluor 568-conjugated anti-mouse IgG (Invitrogen, Carlsbad, CA). The cell nuclei were labeled with mounting medium containing DAPI (Vector, Burlingame, CA). FITC-conjugated phalloidin (Sigma) was applied for $40 \mathrm{~min}$ at room temperature to reveal filamentous actin. Images were obtained using the 'All-In-One Immunofluorescence Microscopy’ system (Keyence Inc., Tokyo, Japan).

Western blotting. After incubation with or without the indicated drugs for $48 \mathrm{~h}$, cellular proteins were resolved using SDSPAGE and then transferred to nitrocellulose membranes. The membranes were incubated with anti-mouse vimentin (1:1000, Chemicon, Billerica, MA), or anti-mouse E-cadherin (1:2500, BD Transduction Laboratories, San Jose, CA). Antibodies against $B$-actin (1:5000, abcam, Tokyo, Japan) were used as an internal control. The proteins were detected using electro-chemiluminescence techniques (Pierce Chemicals, IL). Densitometric quantification was performed using Image Quant 5.2 (GE Healthcare, Piscataway, NJ).

Uptake of low-density lipoprotein $(L D L)$. Cells were cultured in serum-free DMEM containing $1 \%$ bovine serum albumin with $0.1 \%$ DMSO (control) or $50 \mathrm{nM}$ TPA for $24 \mathrm{~h}$, or with $4 \mathrm{nM} \mathrm{HCl}$ (control) or $1 \mathrm{ng} / \mathrm{ml} \mathrm{TGF}-\beta 1$ for $48 \mathrm{~h}$. Cells were incubated with $1 \mu \mathrm{g} / \mathrm{ml} \mathrm{3,3'-dioctadecylindocarbocyanin}$
(Dil)-LDL (Biomedical Technologies, Stoughton, MA) and $10 \mu \mathrm{g} / \mathrm{ml}$ of human LDL (Biomedical Technologies) for $20 \mathrm{~min}$ at $37^{\circ} \mathrm{C}$, then fixed with $4 \%$ paraformaldehyde. After antimouse PIVKA-II was applied overnight, monolayer was incubated with FITC anti-mouse IgG (Sigma).

Fluorescence-activated cell-sorting (FACS) analysis. Cells were cultured in serum-free DMEM containing $1 \%$ bovine serum albumin with $50 \mathrm{nM}$ TPA, $1 \mathrm{ng} / \mathrm{ml}$ TGF- 31 or each control. Cells were incubated with human LDL receptor antibody (Acris-antibodies, Hiddenhausen, Germany) on ice for $15 \mathrm{~min}$. After FITC-conjugated anti-rabbit IgG (Sigma) was applied, cells were subjected to FACS analysis. The stained cells were analyzed using FACSCalibur and CellQuest software (Becton-Dickinson, San Jose, CA).

Filamentous $(F)$ actin/globular $(G)$ actin in vivo assay. The ratio of $\mathrm{F}$ actin versus $\mathrm{G}$ actin was analyzed using an $\mathrm{F}$ actin/G actin in vivo assay kit (Cytoskeleton Inc., Denver, CO) according to the manufacturer's instructions. Briefly, cells were lysed using a cell lysis and F actin stabilization buffer, and homogenized using $25 \mathrm{G}$ syringes. The cell lysates were centrifuged at $100000 \mathrm{~g}$ for $60 \mathrm{~min}$ at $37^{\circ} \mathrm{C}$. The supernatants ( $\mathrm{G}$ actin) were separated from the pellets (F actin). The pellets were resuspended to the same volume as the supernatants using ice-cold distilled water containing $10 \mu \mathrm{M}$ cyto-chalasin $\mathrm{D}$ and were incubated on ice for $60 \mathrm{~min}$. The samples were analyzed by Western blotting. The ratio of $F$ actin versus $G$ actin was quantified using Image Quant 5.2 (GE Healthcare).

Immunohistochemical studies of human HCC samples. Surgically resected specimens were collected between 2005-2007 at Jichi Medical University Hospital and Koseiren Suzuka Chuo Hospital, Japan. The Ethics Committees of both hospitals approved the protocol. Both serum DCP and AFP were measured in all patients. Paraffin-embedded samples were consecutively prepared as $4-\mu \mathrm{m}$ sections and routinely stained with hematoxylin \& eosin (H\&E). The specimens were examined immunohistochemically by the avidin-biotin complex (ABC) method. Anti-mouse E-cadherin (1:400, BD Transduction Laboratories) and anti-mouse PIVKA-II (1:100) were used as primary antibodies. An ABC kit was obtained from Vector Laboratories. The sections were retrieved by autoclaving. After blocking endogenous peroxidase activity by $0.3 \% \mathrm{H}_{2} \mathrm{O}_{2}$, each primary antibody was applied and reacted overnight at room temperature. For color development, $0.05 \%$ wt/vol 3,3'-diamino-benzidine tetrahydrochloride (DAB) was used. The sections were counterstained with hematoxylin. The immunohistochemical staining intensity, as well as the histological grade of HCC, was evaluated independently by three authors (K. Murata, H. Suzuki and A. Sakamoto) without providing them with any clinical information. Staining intensity of DCP or E-cadherin was graded as follows: 0 , negative; 1 , weakly positive; 2 , moderately positive; and 3 , strongly positive. The staining intensity of E-cadherin was evaluated into 'moderately positive' when the staining intensity was as strong as that for normal hepatocytes. The staining intensity of E-cadherin and DCP were evaluated in the same HCC lesions that showed the strongest DCP staining in the section. 
A

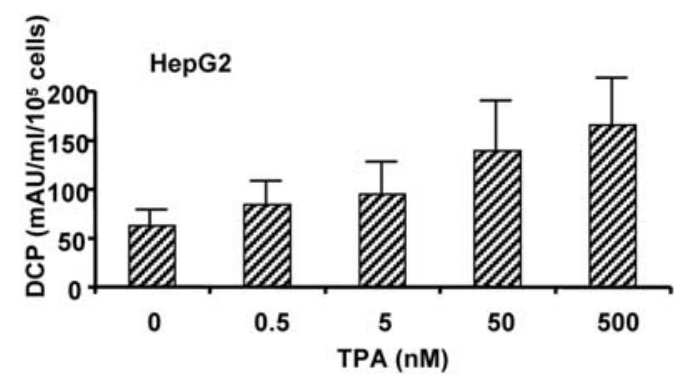

C

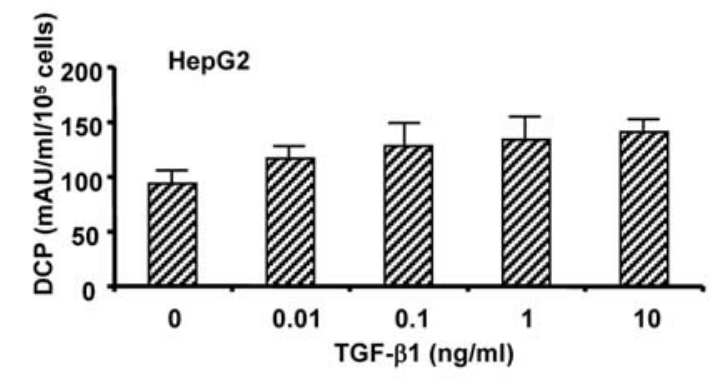

$\mathbf{E}$

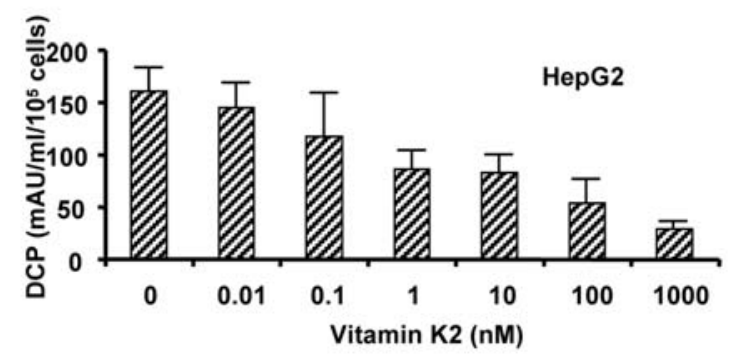

G

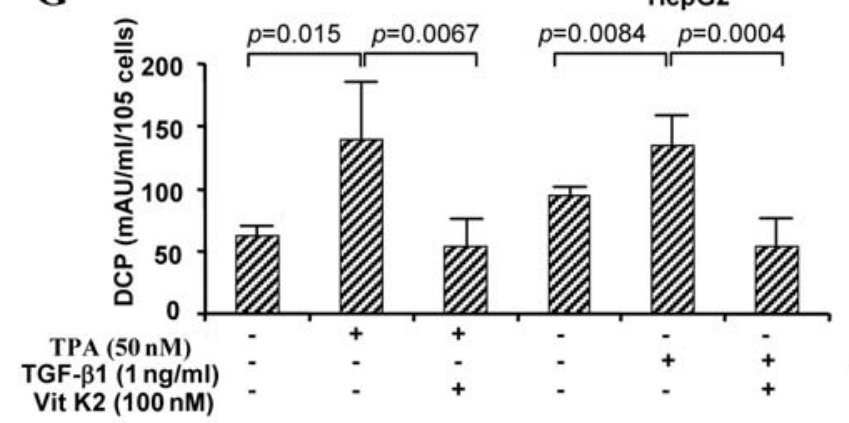

B

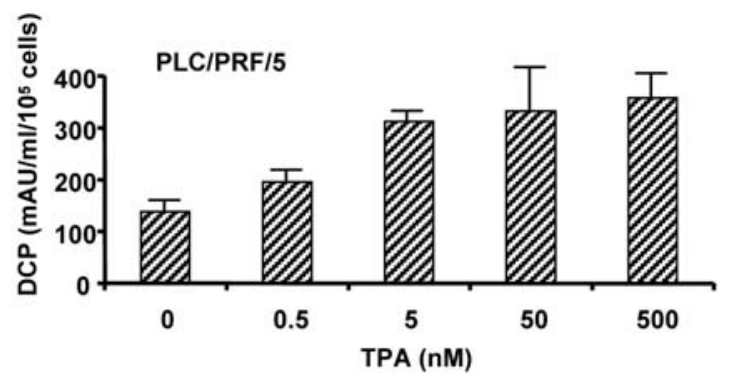

D

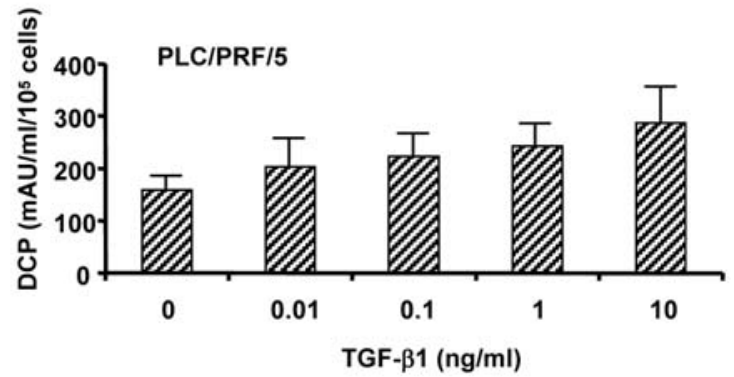

F

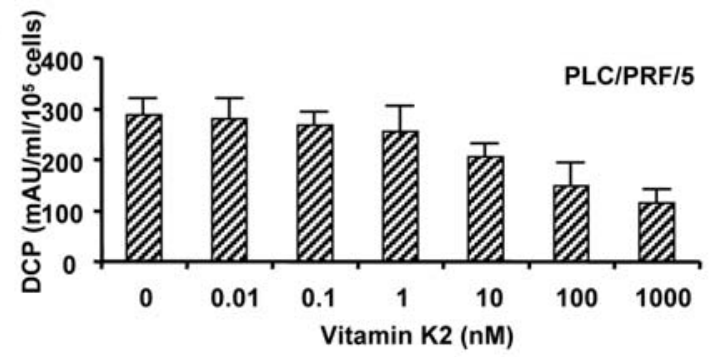

$\mathbf{H}$

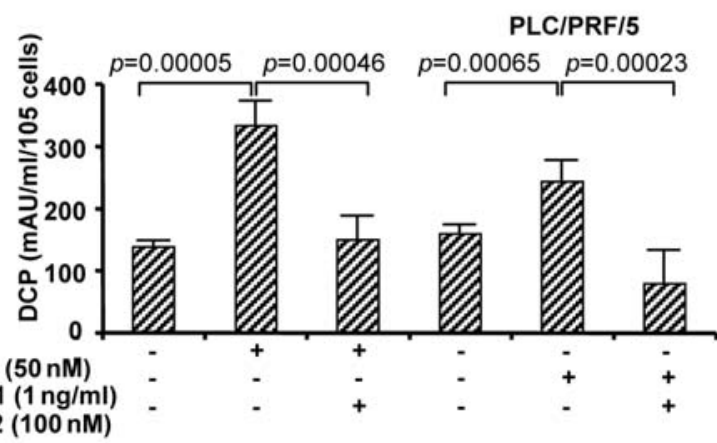

Figure 1. Enzyme-linked immuno-sorbent assay (ELISA). TPA induced DCP production in a dose-dependent manner in HepG2 (A) and PLC/PRF/5 (B) cells $(\mathrm{p}=0.00095, \mathrm{p}<0.00001$, respectively, ANOVA). TGF-ß1 also induced DCP production in a dose-dependent manner in HepG2 (C) and PLC/PRF/5 (D) cells $(\mathrm{p}=0.0098, \mathrm{p}=0.00019$, respectively, ANOVA). Supplementary vitamin K2 inhibited TPA (50 nM)-induced DCP production in a dose-dependent manner in HepG2 (E) and PLC/PRF/5 (F) cells ( $<<0.00001$, p $<0.00001$, respectively, ANOVA). (G and H) A summary of inhibitory effects of vitamin K2 on DCP production in both cells is shown (paired t-test). Values are means \pm SEM.

Statistical analysis. All data are expressed as means \pm SEM. Multiple comparisons were performed using One-way ANOVA. Intergroup comparisons were performed using paired t-tests and Bonferroni's correction for multiple comparisons. Values of $p<0.05$ were considered statistically significant.

\section{Results}

Dose-dependent DCP production by TPA or TGF- $\beta 1$ treatment and effects of vitamin $K 2$ on DCP production. TPA triggers the morphological transition from epithelial to fibroblastic appearance accompanied by scattering and migration of HepG2 cells (12), and TGF-31 promotes conversion to EMT in an HCC cell line (13). Thus, hepatoma cells were treated with TPA or TGF- 11 to induce EMT. Western blotting with MU-3 antibody failed to detect DCP, but ELISA was successful. In fact ELISA demonstrated that TPA treatment significantly induced both HepG2 (Fig. 1A) and PLC/PRF/5 (Fig. 1B) cells to produce DCP in a dose-dependent manner. TGF- 11 also significantly induced both cells to produce 
A

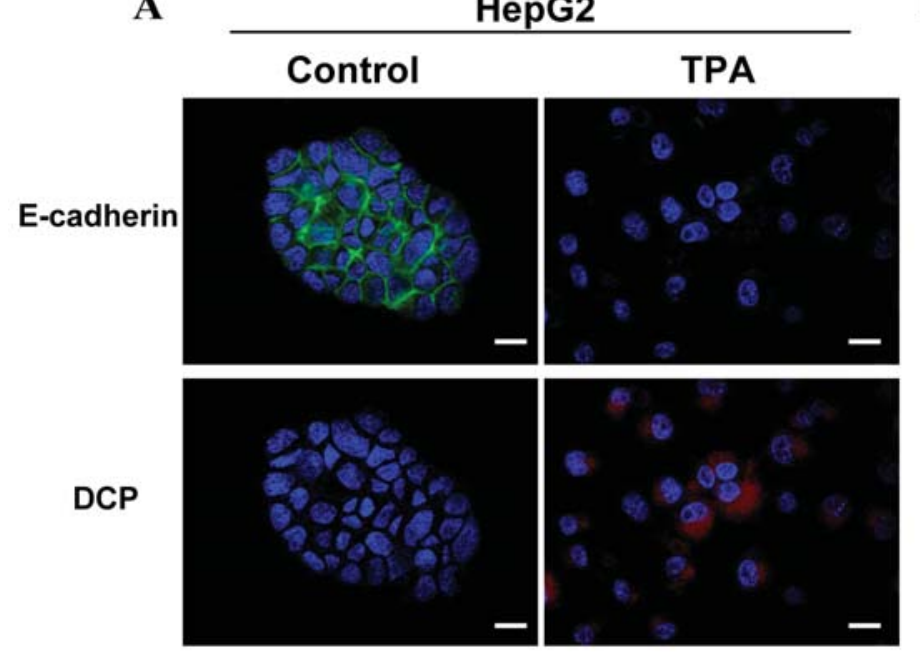

B

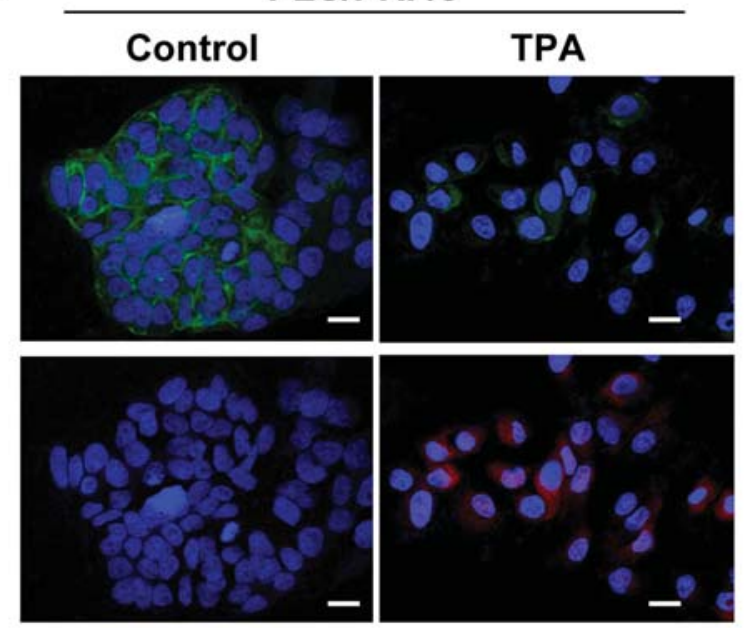

C

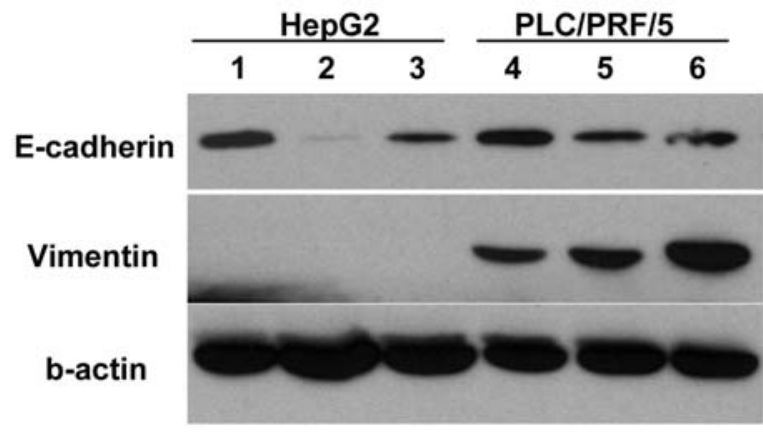

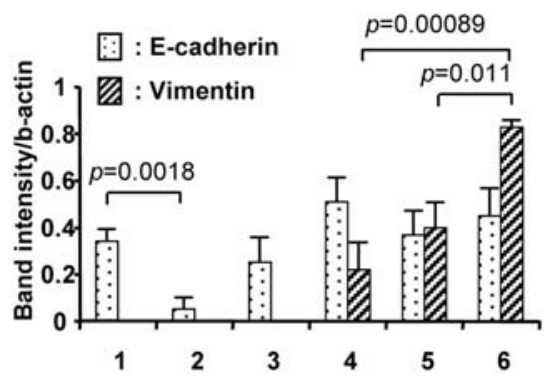

Figure 2. DCP production in cells with reduced E-cadherin expression. (A and B) In an immunofluorescent study, DCP production (red) was observed clearly in TPA-treated cells along with reduced E-cadherin expression. In both control cells, linear E-cadherin expression (green) was observed around the cell boundary. Cell nuclei were stained with DAPI (blue). The bars represent $20 \mu \mathrm{m}$. (C) Western blotting showed that TPA down-regulated E-cadherin expression in both cells in comparison with control cells, but this effect was less prominent in PLC/PRF/5 cells. TGF- 31 up-regulated vimentin expression only in PLC/PRF/5 cells. Lanes 1 and 4, control; lanes 2 and 5, TPA; lanes 3 and 6, TGF-ß1.

DCP in a similar fashion (Fig. 1C and D). DCP production in TPA (50 nM)-treated HepG2 (Fig. 1E) and PLC/PRF/5 (Fig. 1F) cells was significantly inhibited by vitamin $\mathrm{K} 2$ in a dose-dependent manner. As shown in the figures (Fig. 1G and $\mathrm{H})$, DCP production was inhibited by vitamin $\mathrm{K} 2(100 \mathrm{nM})$ in TGF- $31(1 \mathrm{ng} / \mathrm{ml})$-treated cells as well.

DCP production in hepatoma cells following chemical induction of EMT. To confirm whether TPA or TGF- 1 induced hepatoma cells to undergo EMT and whether EMTinduced cells produced DCP, immunofluorescent studies and Western blotting were performed. Immunofluorescent studies demonstrated that TPA reduced E-cadherin expression in both HepG2 (Fig. 2A) and PLC/PRF/5 (Fig. 2B) cells, whereas linear E-cadherin expression around the cell boundary was observed clearly in both control cells. Treated cells became scattered and adopted a fibroblast-like appearance, whereas control cells were round-shaped and clustered. In addition, inhibition of E-cadherin expression in TPA-treated cells resulted in DCP production. Western blotting (Fig. 2C) demonstrated that TPA down-regulated E-cadherin expression in both cell types, but its effect on E-cadherin expression in PLC/PRF/5 cells was less prominent. Treatment with TGF- 31 reduced E-cadherin expression as well, but this effect was weaker than that of TPA in both cell types. By contrast,
TPA and TGF- 31 up-regulated vimentin expression only in $\mathrm{PLC} / \mathrm{PRF} / 5$ cells.

Impairment of LDL uptake in DCP-producing cells. Next, the effect of EFC or EMT on vitamin K uptake in hepatoma cells was examined. As previously reported (11), we used labeledLDL (3,3'-dioctadecylindocarbocyanin LDL: Dil-LDL) as a surrogate for vitamin $\mathrm{K}$ because it is difficult to measure vitamin K uptake directly. Fluorescent studies demonstrated prominent accumulation of Dil-LDL in the cytoplasm of control HepG2 (Fig. 3A) and PLC/PRF/5 (Fig. 3B) cells but not in TPA-treated hepatoma cells. Interestingly, cells with an impairment in Dil-LDL uptake produced DCP, while cells with marked accumulation of Dil-LDL did not produce DCP (Fig. 3A and B). TGF-B1 reduced Dil-LDL uptake and increased DCP production in both cell types, although TGF- 31 did not show a prominent effect on E-cadherin expression (Fig. 2C). The numbers of LDL-receptor were higher after TPA treatment when compared with control cells (Fig. 3C and D) and were similar after TGF-B1 treatment, suggesting that impairment of Dil-LDL uptake in TPA- or TGF-B1-treated cells was not due to a decrease in the numbers of LDL-receptors. Suramin inhibits hepatic uptake of chylomicron remnants through interference with the function of heparin sulfate proteoglycan (HSPG) (15) and significantly 
A

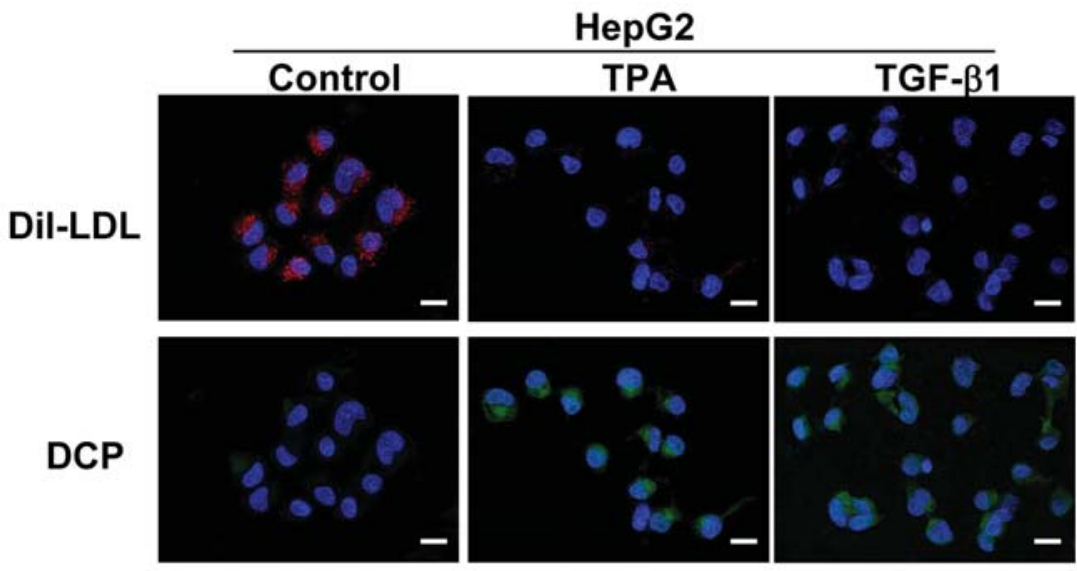

B

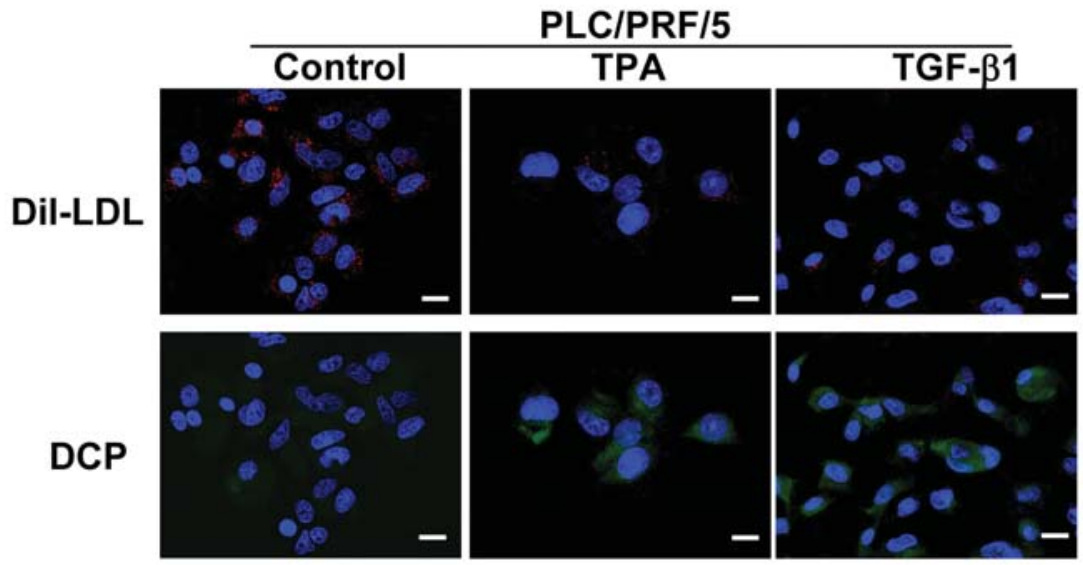

C

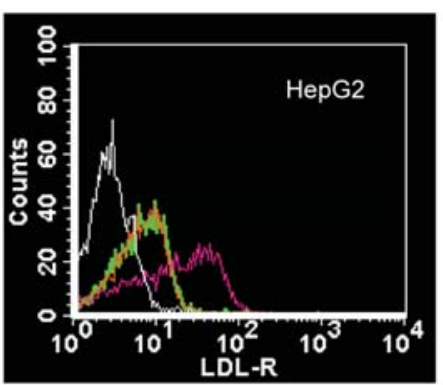

$\mathbf{E}$

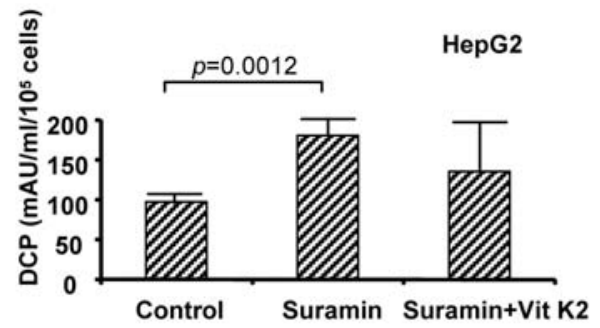

D

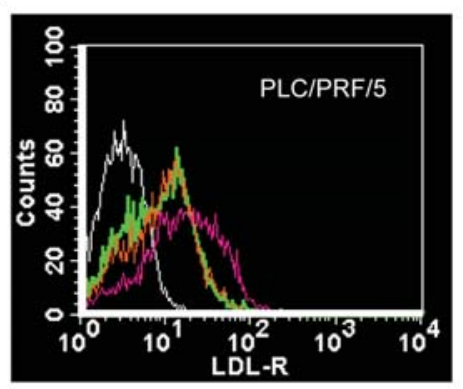

$\mathbf{F} \quad \frac{\bar{m}}{\overline{\frac{\pi}{0}}}$

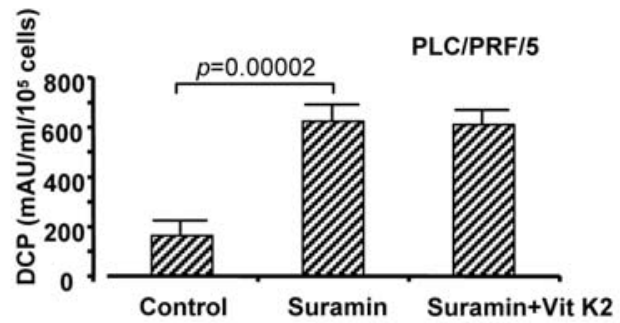

Figure 3. Immunofluorescent studies of Dil-LDL uptake and DCP production. (A and B) Dil-LDL uptake (red) was significantly impaired in both treated-cells in comparison with control cells. Cells with impairment of Dil-LDL uptake produced DCP (green), whereas control cells with well uptake of Dil-LDL did not. Cell nuclei were stained with DAPI (blue). The bars represent $20 \mu \mathrm{m}$. (C and D) FACS demonstrated that the intensity curve was shifted to the right in TPAtreated cells (pink) relative to control cells (green) and was similar in TGF-ß1-treated cells (red). The white curve represents control cells treated with FITCanti-rabbit IgG, but without anti-LDL receptor. (E and F) Suramin $(500 \mu \mathrm{g} / \mathrm{ml}$ ) significantly induced DCP production in both cells (paired t-test) without any inhibitory effects of vitamin $\mathrm{K} 2(100 \mathrm{nM})$. Values are means \pm SEM.

induced DCP production in both cell types without reduced effects of vitamin K2 (Fig. 3E and F).

Filamentous actin rearrangement in DCP-producing cells. Dynamic polymerization of endogenous filamentous $(\mathrm{F})$ actin plays an important role in clathrin-mediated endocytosis, including endocytosis of fat-soluble vitamins (i.e., vitamin K). Therefore, the contribution of cytoskeletal rearrangement during EFC or EMT to DCP production in hepatoma cells was investigated. An immunofluorescent study using FITCconjugated phalloidin revealed a subcortical typical network of $\mathrm{F}$ actin in control HepG2 (Fig. 4A and C) and PLC/PRF/5 

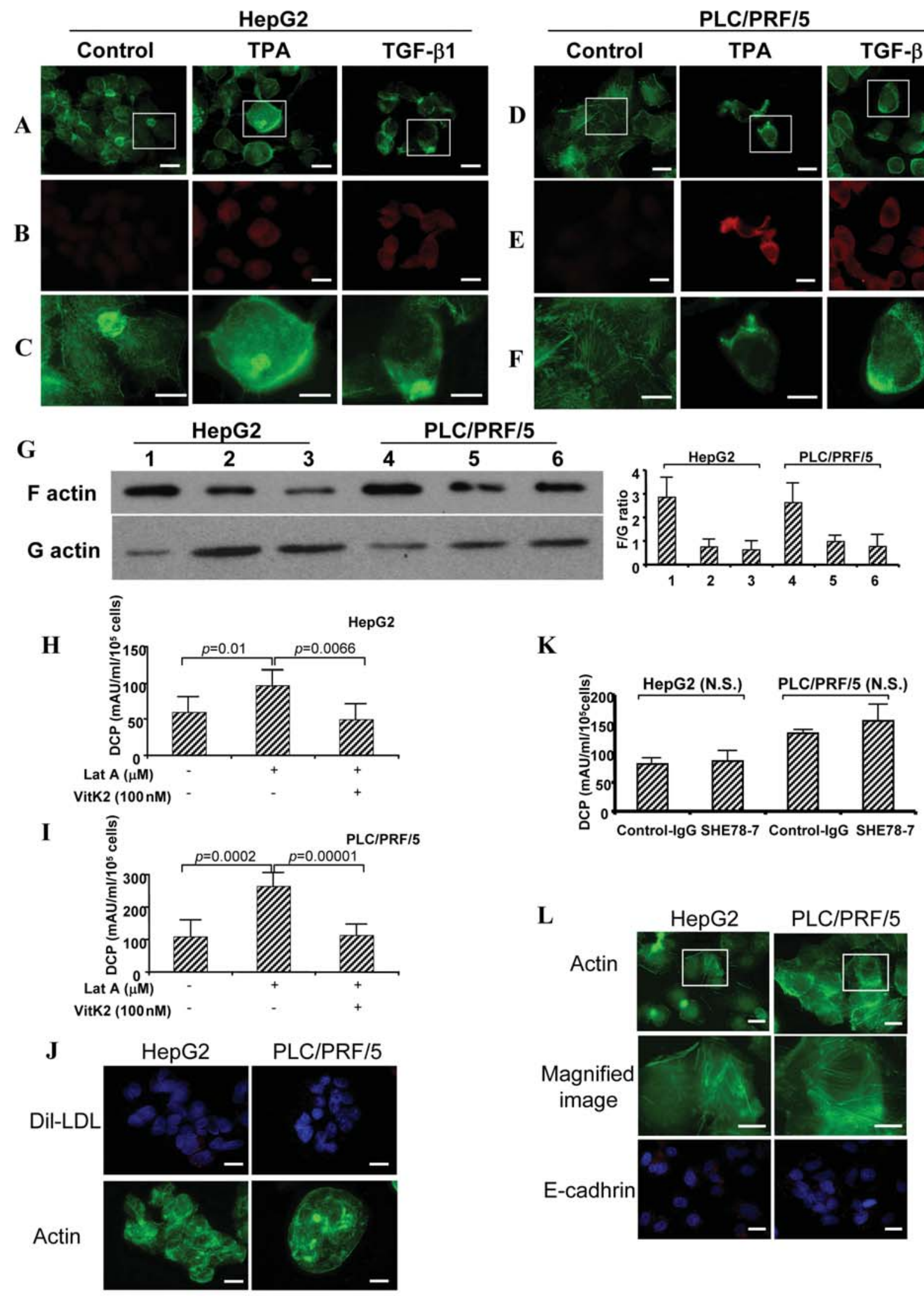

Figure 4. Disruption of F actin and DCP production. (A and D) FITC-conjugated phalloidin staining showed fine linear F actin in control cells, whereas F actin was disrupted in both TPA- and TGF-B1-treated cells. (B and E) Double staining of phalloidin and DCP showed that cells with disrupted F actin produced DCP (red), whereas control cells with fine F actin network did not. (C and F) Magnified images of the inlet of A and D. (G) The amount of F actin was significantly reduced in both TPA- and TGF- $\beta 1$-treated cells relative to control cells (lanes 1 and 4, control; lanes 2 and 5, TPA; lanes 3 and 6, TGF- 31 ). (H and I) Lat A $(1 \mu \mathrm{M})$ induced naïve cells to produce DCP, which was inhibited by $100 \mathrm{nM}$ vitamin K2 (paired t-test). (J) Lat A (1 $\mu \mathrm{M})$ impaired Dil-LDL uptake (red) in both cell types. Fine network of F actin (green) was disappeared in Lat A-treated cells. (K) SHE78-7 (3 $\mu \mathrm{g} / \mathrm{ml})$ did not induce DCP production (NS, paired t-test). (L) SHE78-7 did not affect fine filamentous actin network (green) with loss of linear structures of E-cadherin (red). Cell nuclei were stained with DAPI (blue). The bars represent $20 \mu \mathrm{m}$ except for $\mathrm{E}$ and $\mathrm{F}(10 \mu \mathrm{m})$. Values are means \pm SEM. 
A

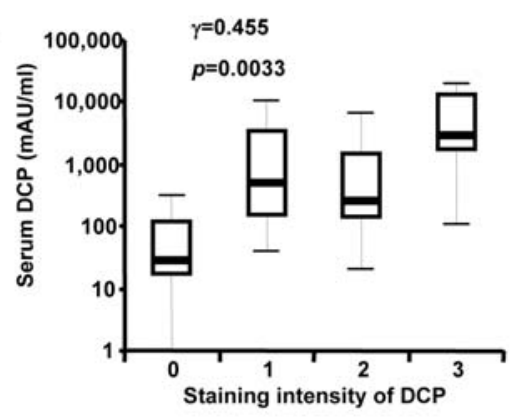

B

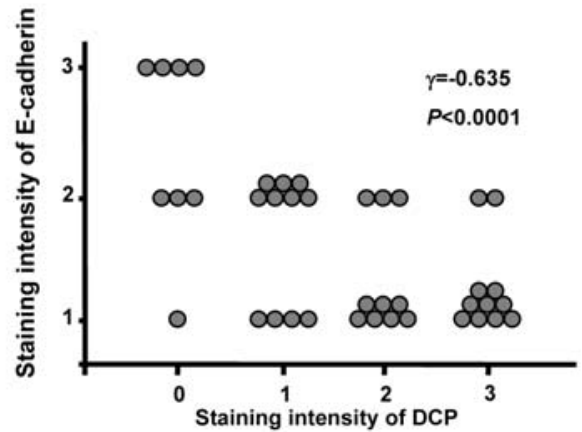

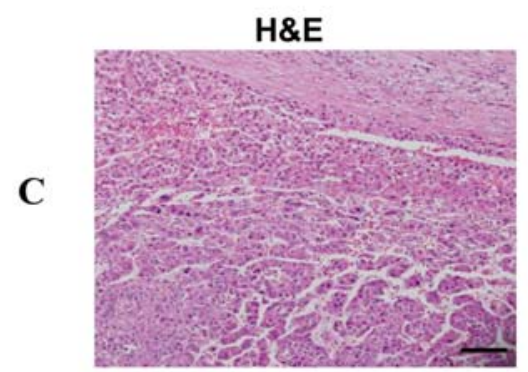
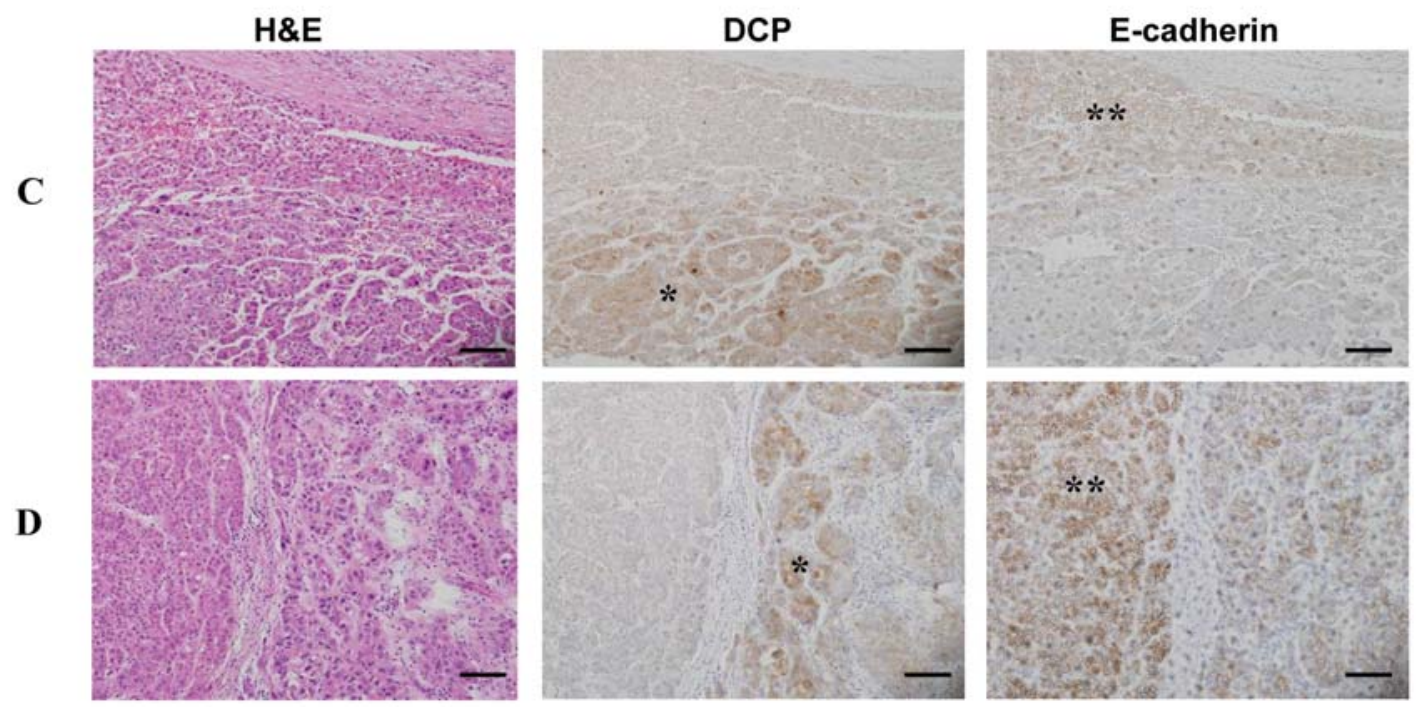

Figure 5. Immunohistochemical studies of E-cadherin and DCP in human HCC. (A) Serum DCP levels correlated with staining intensity of DCP ( $\gamma=0.455$, $\mathrm{p}=0.0033$ ). Staining intensity was classified as negative; 0 , weekly positive; 1 , moderately positive; 2 , and 3 , strongly positive. (B) Staining intensity of DCP was inversely correlated with that of E-cadherin $(\gamma=-0.635, \mathrm{p}<0.0001)$. Typical reciprocal staining patterns of DCP and E-cadherin in case $2(\mathrm{C})$ and case $38(\mathrm{D})$ are shown. *Area with weak staining for E-cadherin in cells that produce DCP. ${ }^{* *}$ Area with strong staining for E-cadherin in cells without DCP production. The bars represent $100 \mu \mathrm{m}$.

(Fig. 4D and F) cells, whereas these structures were disrupted and phalloidin-positive dots were observed after TPA or TGF- 11 treatment. In addition, DCP production was clearly observed in TPA- or TGF-ß1-treated HepG2 (Fig. 4B) and PLC/PRF/5 (Fig. 4E) cells, in which linear F actin structures were absent, whereas DCP production was not observed in the control cells that showed a fine network of $\mathrm{F}$ actin filaments. Further, the amount of $\mathrm{F}$ actin was significantly reduced, and the amount of $G$ actin was significantly increased in TPAand TGF-ß1-treated cells relative to control cells (Fig. 4G). To confirm the contribution of $\mathrm{F}$ actin disruption to DCP production, naïve HepG2 and PLC/PRF/5 cells were treated with latrunculin A (Lat A), an actin depolymerizer. Lat A treatment significantly induced DCP production in naïve HepG2 (Fig. 4H) and PLC/PRF/5 (Fig. 4I) cells. In addition, Lat A-induced DCP production was inhibited by administration of vitamin K2 (100 nM) in both cell types (Fig. 4H and I). Further, Lat A treatment resulted in impairments in Dil-LDL uptake in both cell types (Fig. 4J). To determine whether E-cadherin expression directly contributes to DCP production, hepatoma cells were treated with SHE78-7, a neutralizing antibody against human E-cadherin. Linear E-cadherin expression around the cell boundary disappeared after SHE78-7 treatment. SHE78-7 treatment alone did not induce
DCP production (Fig. 4K). In addition, liner F actin network was clearly observed after SHE78-7 treatment in both cell types (Fig. 4L), suggesting that inhibition of E-cadherin expression alone did not affect $\mathrm{F}$ actin structure and is therefore not an essential mechanism for DCP production.

Immunohistochemical study of E-cadherin and DCP in human HCC samples. A total of 40 patients with surgically resected HCC were included in this study. Characteristic features of enrolled patients are summarized in Table I. The median age was $66 \pm 11$ years (male:female $=29: 11$ ) at the time of operation. The cause of chronic liver disease was hepatitis B infection $(n=8)$, hepatitis $C$ infection $(n=23)$ and cryptogenic cirrhosis $(n=9)$. Serum DCP levels were higher in patients with moderately- or poorly-differentiated HCC than those in patients with well-differentiated HCC $(5329 \pm 6344 \mathrm{mAU} / \mathrm{ml}$, $272 \pm 653 \mathrm{mAU} / \mathrm{ml}$, respectively, $\mathrm{p}=0.0031$ ). Serum DCP was significantly higher in patients with vascular invasion than those without $(5992 \pm 7026 \mathrm{mAU} / \mathrm{ml}, 1100 \pm 2318 \mathrm{mAU} / \mathrm{ml}$, respectively, $\mathrm{p}=0.0033$ ), which is consistent with prior reports $(16,17)$. Immunohistochemistry demonstrated that the staining intensity of DCP correlated with the level of serum DCP in HCC patients $(\gamma=0.455, \mathrm{p}=0.0033)$ (Fig. 5A). $\mathrm{DCP}$ and E-cadherin were not homogenously stained, even in 
Table I. Patient characteristics.

\begin{tabular}{|c|c|c|c|c|c|c|}
\hline No. & Age & Cause & DCP & AFP & Histological grade & Vascular invasion \\
\hline 1. & 70 & $\mathrm{C}$ & 24 & 12 & W & - \\
\hline 2. & 72 & $\mathrm{C}$ & 9,595 & 55,980 & M & - \\
\hline 3. & 60 & $\mathrm{C}$ & 3,564 & 20 & $\mathrm{P}$ & + \\
\hline 4. & 40 & B & 508 & 2,131 & $\mathrm{M}$ & + \\
\hline 5. & 55 & $\mathrm{~B}$ & 2,692 & 45 & $\mathrm{~W}$ & - \\
\hline 6. & 64 & NBNC & 42 & 15 & $\mathrm{~W}$ & - \\
\hline 7. & 75 & NBNC & 217 & 4 & $\mathrm{~W}$ & - \\
\hline 8. & 65 & $\mathrm{C}$ & 20 & 5 & $\mathrm{~W}$ & - \\
\hline 9. & 78 & B & 11,266 & 2 & $\mathrm{M}$ & + \\
\hline 10. & 77 & $\mathrm{C}$ & 139 & 396 & $\mathrm{P}-\mathrm{M}$ & + \\
\hline 11. & 71 & $\mathrm{C}$ & 18,192 & 15 & $\mathrm{M}$ & ++ \\
\hline 12. & 76 & $\mathrm{C}$ & 113 & 24 & $\mathrm{~W}$ & - \\
\hline 13. & 74 & NBNC & 5,900 & 3 & M & + \\
\hline 14. & 63 & NBNC & 696 & 8 & $\mathrm{M}$ & - \\
\hline 15. & 65 & $\mathrm{C}$ & 1,735 & 210 & M-P & - \\
\hline 16. & 78 & $\mathrm{C}$ & 18 & 2,272 & W & - \\
\hline 17. & 71 & $\mathrm{C}$ & 15 & 70 & $\mathrm{~W}$ & - \\
\hline 18. & 70 & $\mathrm{C}$ & 985 & 18,090 & M-P & + \\
\hline 19. & 69 & $\mathrm{C}$ & 205 & 52 & W & - \\
\hline 20. & 65 & $\mathrm{C}$ & 469 & 192 & $\mathrm{M}$ & - \\
\hline 21. & 70 & $\mathrm{C}$ & 321 & 24 & $\mathrm{M}$ & - \\
\hline 22. & 71 & $\mathrm{C}$ & 52 & 13 & $\mathrm{~W}$ & - \\
\hline 23. & 44 & B & 274 & 50,000 & $\mathrm{~W}$ & - \\
\hline 24. & 62 & NBNC & 1,880 & 1,060 & $\mathrm{M}$ & + \\
\hline 25. & 40 & B & 16,500 & 50,000 & M-P & + \\
\hline 26. & 74 & $\mathrm{C}$ & 2,340 & 31 & M & - \\
\hline 27. & 79 & NBNC & 6,520 & 4 & $\mathrm{M}$ & - \\
\hline 28. & 51 & B & 339 & 67,600 & $\mathrm{~W}$ & - \\
\hline 29. & 78 & $\mathrm{C}$ & 1,872 & 60 & $\mathrm{M}$ & - \\
\hline 30. & 74 & $\mathrm{C}$ & 83 & 5 & $\mathrm{~W}$ & - \\
\hline 31. & 71 & B & 71 & 2 & W & + \\
\hline 32. & 56 & $\mathrm{C}$ & 10,734 & 14 & M-P & + \\
\hline 33. & 59 & B & 8,343 & 59,633 & $\mathrm{M}$ & + \\
\hline 34. & 69 & NBNC & 1 & 2,772 & $\mathrm{M}$ & + \\
\hline 35. & 70 & C & 250 & 52 & $\mathrm{M}$ & + \\
\hline 36 & 75 & $\mathrm{C}$ & 20,629 & 43,088 & P-M & + \\
\hline 37. & 68 & C & 21 & 514 & $\mathrm{~W}$ & - \\
\hline 38. & 55 & NBNC & 108 & 64 & M-P & - \\
\hline 39. & 47 & NBNC & 360 & 6 & $\mathrm{M}$ & - \\
\hline 40. & 73 & $\mathrm{C}$ & 159 & 20,109 & W & - \\
\hline
\end{tabular}

W: well-, M: moderate-, P: poorly-differentiated.

the same lesion. Interestingly, the staining intensity of Ecadherin negatively correlated with the staining intensity of DCP in the same lesions $(\gamma=-0.635, \mathrm{p}<0.0001)$ (Fig. 5B). Typical staining patterns are shown in Fig. 5C (case 2) and Fig. 5D (case 38). In these cases, DCP production was observed in HCC cells with weak staining intensity of Ecadherin, whereas DCP production was not observed in HCC cells with strong staining intensity of E-cadherin. These findings are consistent with observations from our in vitro experiments. 


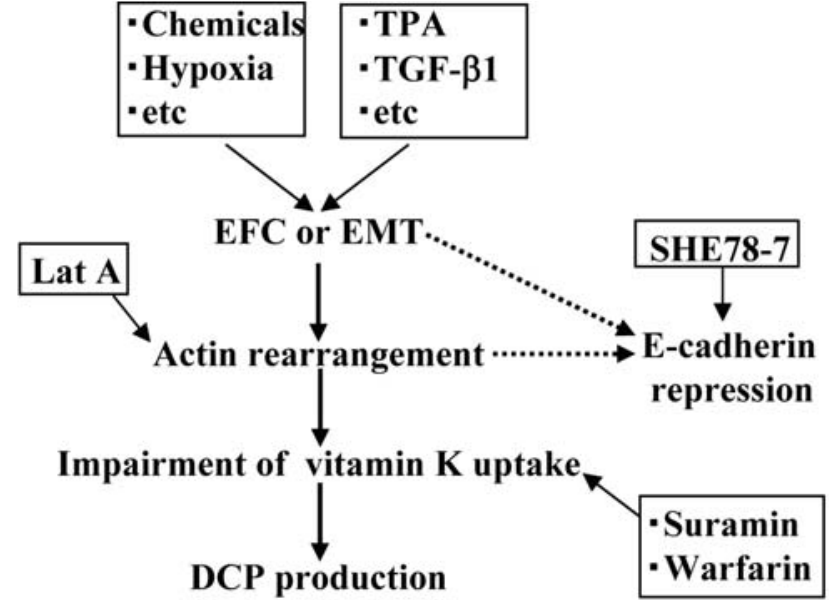

Figure 6. Schematic summary of proposed mechanism for DCP production in $\mathrm{HCC}$ cells

\section{Discussion}

DCP is a well-known tumor marker for HCC, but the precise mechanism underlying DCP production in HCC cells remains unclear. By contrast to AFP and other tumor markers, DCP levels can be reduced (via administration of vitamin K2 analogues) without decreasing tumor burden (14), which was confirmed in vitro (18). Importantly, DCP is not specific for HCC, as all hepatocytes can produce DCP in the absence of vitamin $\mathrm{K}$ action (2) such as with vitamin $\mathrm{K}$ nutritional deficiencies or following warfarin administration. It is also well known that vitamin K-rich foods reduce the effect of warfarin (19). The above evidence led us to the hypothesis that vitamin $\mathrm{K}$ uptake is impaired in DCP producing HCC cells. Indeed, the present study demonstrated that TPA- or TGF-ß1-induced morphological changes into EFC or EMT resulted in impairments in Dil-LDL uptake and enhanced DCP production. Further, functional inhibition of HSPG by suramin induced DCP production in hepatoma cells.

Actin-based cytoskeleton reorganization is required to reshape the plasma membrane, including different forms of endocytic internalization and the protrusion of lamellipodia or filopodia during cell migration (20-22). Particularly with endocytic processes, the polymerization of actin provides the force for the deformation and movement of a membrane at different steps (21). Fat-soluble vitamins (including vitamin K) are taken up into cells through clathrin-mediated endocytic internalization (23), in which the dynamic polymerization of endogenous $\mathrm{F}$ actin plays a crucial role $(24,25)$. In the present study, TPA- or TGF-B1-treatment resulted in the loss of the fine network of phalloidin-positive F actin (Fig. 5). Actin rearrangement during TPA or TGF- $\$ 1$ treatment was confirmed by $\mathrm{F}$ actin/G actin in an in vivo assay (Fig. 4G). Further, the present study found that cells with actin rearrangement produced DCP, whereas DCP production was not observed in cells with liner $\mathrm{F}$ actin structure. In addition, Lat $\mathrm{A}$, an actin depolymerizer, induced naïve hepatoma cells to produce DCP and induced an impairment in Dil-LDL uptake, suggesting that polymerization of $\mathrm{F}$ actin is required for vitamin $\mathrm{K}$ uptake and that impairment of $\mathrm{F}$ actin polymerization results in DCP production.
Down-regulation of E-cadherin,which is a central component of cell-cell adhesion junctions, is involved in the early recurrence of HCC after surgical treatment (26) or metastasis (27). Vimentin is also expressed in migrating epithelial cells, such as in the context of wound healing (28) or tumor invasion $(29,30)$. Vimentin expression in cancer cells is associated with tumor metastases $(29,31)$. Thus, both E-cadherin downregulation and vimentin up-regulation are associated with tumor spread. Since high serum DCP in HCC patients is well associated with tumor spread $(16,32,33)$, DCP-producing HCC cells might be a migratory or invasive phenotype. Indeed, the present study demonstrated that hepatoma cells produced DCP when they morphologically changed their phenotype to EFC or EMT. In Western blotting, different effects of TPA or TGF- 11 on E-cadherin or vimentin expression were observed between the two cell lines. Since vimentin expression levels in each naïve cell is different, naïve HepG2 cells might have strong epithelial characteristics whereas naïve PLC/PRF/5 cells might have characteristics intermediate between those epithelial and mesenchymal phenotypes, which may explain those different effects. However, both treatments induced hepatoma cells to produce DCP, regardless of their effects on E-cadherin or vimentin expression. In addition, treatment with SHE78-7, a neutralizing antibody against human E-cadherin, did not induce DCP production and did not affect $\mathrm{F}$ actin structures. Therefore, E-cadherin down-regulation or vimentin upregulation does not appear to be essential for DCP production.

Immunohistochemical studies demonstrated inverse correlation between DCP production and E-cadherin expression in surgically resected specimens. However, DCP-producing HCC cells did not always show reduced E-cadherin expression. Since the present in vitro study demonstrated that cytoskeletal changes, not E-cadherin repression, might have crucial role for DCP production, actin rearrangement may affect the juxtamembrane region of E-cadherin, thereby altering E-cadherin expression in DCP-producing HCC cells rather than direct effects of reduced E-cadherin expression on DCP production. Other investigators have reported that E-cadherin attaches to the cytoskeleton via connections to several cytoplasmic proteins, including B-catenins (34), although the mechanistic link between E-cadherin expression and cytoskeletal rearrangement remains unclear. The present study was unable to directly investigate the association between DCP production and actin rearrangement in human HCC samples. This is because it is difficult to stain $\mathrm{F}$ actin in formalin-fixed tissues and because $\mathrm{F}$ actin is unstable and is easily depolymerized. In addition, extracellular matrix within the HCC samples also contains $\mathrm{F}$ actin, making it difficult to assess HCC F actin content. However, further investigation is necessary to address this issue.

The reduction of DCP production by vitamin K2 in TPA-, TGF-B1- or Lat A-treated cells is due to supplementary effects, not due to cytotoxic effects, as the dose of vitamin $\mathrm{K} 2$ required to reduce DCP levels $(<100 \mathrm{nM})$ is less than that required to inhibit HCC cell growth $(50-100 \mu \mathrm{M})(13)$. $\mathrm{F}$ actin is critical for endocytosis in yeasts (35). However, in mammalian cells, $\mathrm{F}$ actin has a facilitatory rather than an essential role in endocytosis (36). In addition, inhibition of endocytosis in mammalian cells by Lat A tends to reduce the rate of internalization rather than blocking it completely 
(37). This evidence suggests that mammalian cells have actin-independent pathway for endocytosis. Therefore, it is possible that supplementary vitamin $\mathrm{K} 2$ is taken up through a functionally impaired-F actin dependent pathway or through an F actin-independent pathway in DCP-producing HCC and that additional vitamin $\mathrm{K} 2$ may recover total uptake into the cells.

Taken together, the present study demonstrated that phenotypic changes of hepatoma cells during EFC or EMT resulted in enhanced DCP production via impairments of vitamin $\mathrm{K}$ uptake, as reflected by decreased labeled-LDL uptake and cytoskeletal rearrangement (Fig. 6). Importantly, this mechanistic notion is consistent with substantial clinical evidence $(14,16,17,26,32,33)$.

\section{Acknowledgements}

This work was supported in part by a Grant-in-Aid for Scientific Research from the Japan Society. We thank Dr T. Murata of the pathology section at Suzuka Chuo Hospital for providing paraffin sections of surgically resected HCC.

\section{References}

1. Liebman HA, Furie BC and Furie B: Hepatic vitamin K-dependent carboxylation of blood-clotting proteins. Hepatology 2: 488-494, 1982.

2. Blanchard RA, Furie BC, Jorgensen M, Kruger SF and Furie B: Acquired vitamin K-dependent carboxylation deficiency in liver disease. N Eng J Med 305: 242-248, 1981.

3. Liebman HA, Furie BC, Tong MJ, et al: Des- $\gamma$-carboxy (abnormal) prothrombin as a serum marker of primary hepatocellular carcinoma. N Eng J Med 310: 1427-1431, 1984.

4. Shah DV, Engelke JA and Suttie JW: Abnormal prothrombin in the plasma of rats carrying hepatic tumors. Blood 69: 850-854, 1987.

5. Ono M, Ohta H, Ohhira M, Sekiya C and Namiki M: Measurement of immunoreactive prothrombin, des-gamma-carboxy prothrombin, and vitamin $\mathrm{K}$ in human liver tissues: overproduction of immunoreactive prothrombin in hepatocellular carcinoma. Am J Gastroenterol 85: 1149-1154, 1990.

6. Huisse MG, Leclercq M, Belghiti J, et al: Mechanism of the abnormal vitamin K-dependent gamma-carboxylation process in human hepatocellular carcinomas. Cancer 74: 1533-1541, 1994.

7. Kruchten AE and McNiven MA: Dynamin as a mover and pincher during cell migration and invasion. J Cell Sci 119 1683-1690, 2006.

8. Yang AD, Fan F, Camp ER, et al: Chronic oxaliplatin resistance induces epithelial-to- mesenchymal transition in colorectal cancer cell lines. Clin Cancer Res 12: 4147-4153, 2006.

9. Cannito S, Novo E, Compagnone A, et al: Redox mechanisms switch on hypoxia-dependent epithelial-mesenchymal transition in cancer cells. Carcinogenesis 29: 2267-2278, 2008.

10. Thiery JP and Sleeman JP: Complex networks orchestrate epithelial-mesenchymal transitions. Nat Rev Mol Cell Biol 7: 131-142, 2006

11. Murata K and Sakamoto A: Impairment of clathrin-mediated endocytosis via cytoskeletal change by epithelial to fibroblastoid conversion in HepG2 cells: a possible mechanism of des- $\gamma$ carboxy prothrombin production in hepatocellular carcinoma. Int J Oncol 33: 1149-1155, 2008.

12. Wu WS, Tsai RK, Chang CH, Wang S, Wu JR and Chang YX: Reactive oxygen species mediated sustained activation of protein kinase $\mathrm{C} \alpha$ and extracellular signal-regulated kinase for migration of human hepatoma cell HepG2. Mol Cancer Res 4: 747-758, 2006

13. Xu Z, Shen MX, Ma DZ, Wang LY and Zha ZL: TGF-ß1promoted epithelial-to-mesenchymal transformation and cell adhesion contribute to TGF- $B 1$-enhanced cell migration in SMMC-7721 cells. Cell Res 13: 343-350, 2003.

14. Mizuta T, Ozaki I, Eguchi Y, et al: The effect of menatetrenone, a vitamin $\mathrm{K} 2$ analog, on disease recurrence and survival in patients with hepatocellular carcinoma after curative treatment. Cancer 106: 867-872, 2006
15. Zeng BJ, Mortimer BC, Martins IJ, Seydel U and Redgrave TG: Chylomicron remnant uptake is regulated by the expression and function of heparin sulfate proteoglycan in hepatocytes. J Lipid Res 39: 845-860, 1998.

16. Koike Y, Shiratori Y, Sato S, et al: Des- $\gamma$-carboxy prothrombin as a useful predisposing factor for the development of portal venous invasion in patients with hepatocellular carcinoma. Cancer 91: 561-569, 2001.

17. Shirabe K, Itoh S, Yoshizumi T, et al: The predictors of microvascular invasion in candidates for liver transplantation with hepatocellular carcinoma-with special reference to the serum levels of des-gamma-carboxy prothrombin. J Surg Oncol 95: 235-240, 2007.

18. Wang Z, Wang M, Finn F and Carr BI: The growth inhibitory effects of vitamin $\mathrm{K}$ and their actions on gene expression. Hepatology 22: 876-882, 1995.

19. Hirsh J: Current anticoagulant therapy-unmet clinical needs. Thromb Res 109: S1-S8, 2003.

20. Savagner P: Leaving the neighborhood: molecular mechanisms involved during epithelial-mesenchymal transition. Bioessays 23: 912-923, 2001.

21. Kaksonen M, Toret CP and Drubin DG: Harnessing actin dynamics for clathrin-mediated endocytosis. Nat Rev Mol Cell Biol 7: 404-414, 2006.

22. Engqvist-Goldstein AE and Drubin DG: Actin assembly and endocytosis: from yeast to mammalians. Annu Rev Cell Dev Biol 19: 287-332, 2003.

23. Goldstein JL, Anderson RGW and Brown MS: Coated pits, coated vesicles, and receptor-mediated endocytosis. Nature 279: 679-685, 1979.

24. Merrifield CJ, Feldman ME, Wan L and Almers W: Imaging actin and dynamin recruitment during invagination of single clathrin-coated pit. Nat Cell Biol 4: 691-698, 2002.

25. Yarar D, Waterman-Storer CM and Schmid SL: A dynamic actin cytoskeleton functions at multiple stages of clathrinmediated endocytosis. Mol Biol Cell 16: 964-975, 2005.

26. Inayoshi J, Ichida T, Sugitani S, et al: Gross appearance of hepatocellular carcinoma reflects E-cadherin expression and risk of early recurrence after surgical treatment. J Gastroenterol Hepatol 18: 673-677, 2003.

27. Lee TK, Poon RTP, Yuen AP, et al: Twist overexpression correlates with hepatocellualr carcinoma metastasis through induction of epithelial-mesenchymal transition. Clin Cancer Res 12: 5369-5376, 2006.

28. Gilles C, Polette M, Zahm JM, et al: Vimentin contributes to human mammary epithelial cell migration. J Cell Sci 112: 4615-4625, 1999.

29. Gilles C, Polette M, Piette J, et al: Vimentin expression in cervical carcinomas: association with the invasive and the migratory phenotype of tumor cells. J Pathol 180: 175-180, 1996.

30. Ramaekers FC, Haag D, Kant A, Moesker O, Jap PHK and Vooijs GP: Coexpression of keratin- and vimentin-intermediate filaments in human metastatic carcinoma cells. Proc Natl Acad Sci USA 80: 2618-2622, 1983.

31. $\mathrm{Hu} \mathrm{L}$, Lau SH, Tzang CH, et al: Asssociation of vimentin overexpression and hepatocellular carcinoma. Oncogene 23: 298-302, 2004.

32. Suehiro T, Matsumata T, Itasaka H, Taketomi A, Yamamoto $\mathrm{K}$ and Sugimachi K: Des-gamma-carboxy prothrombin and proliferative activity of hepatocellular carcinoma. Surgery 117: 682-691, 1995.

33. Shimada M, Yonemura Y, Ijichi H, et al: Living donor liver transplantation for hepatocellular carcinoma: a special reference to a preoperative Des-gamma-carboxy prothrombin value. Transplant Proc 37: 1177-1179, 2005.

34. Noren NK, Liu BP, Burridge K and Kreft B: p120 catenin regulates the actin cytoskeleton via Rho GTPases. J Cell Biol 150: 567-579, 2000.

35. Ayscough KR, Stryker J, Pokala N, Sanders M, Crews P and Drubin DG: High rates of actin filament turnover in budding yeast and roles for actin in establishment and maintenance of cell polarity revealed using the actin inhibitor latrunculin-A. J Cell Sci 137: 399-416, 1997.

36. Fujimoto LM, Roth R, Heuser JE and Schmid SL: Actin assembly plays a variable, but not obligatory role in receptormediated endocytosis in mammalian cells. Traffic 1: 161-171, 2000.

37. Smythe E and Ayscough KR: Actin regulation in endocytosis. J Cell Sci 119: 4589-4598, 2006. 